\title{
Article
}

\section{Principles of Surgical Management of Small Intestinal NET}

\author{
Arnaud Pasquer ${ }^{1,2, *(\mathbb{D}}$, Thomas Walter ${ }^{2,3,4}$ (D) , Laurent Milot ${ }^{2,3,5}$, Valérie Hervieu ${ }^{2,3,6}$ and Gilles Poncet ${ }^{1,2,3}$ \\ 1 Service de Chirurgie Digestive, Hôpital Edouard Herriot, Hospices Civils de Lyon, F69437 Lyon, France; \\ gilles.poncet@chu-lyon.fr \\ 2 Université de Lyon, Université Claude Bernard Lyon 1, F69100 Villeurbanne, France; \\ thomas.walter@chu-lyon.fr (T.W.); laurent.milot@chu-lyon.fr (L.M.); valerie.hervieu@chu-lyon.fr (V.H.) \\ 3 INSERM, UMR 1052-UMR5286, UMR 1032 Lyon Cancer Research Center, Faculté Laennec, \\ F69437 Lyon, France \\ 4 Service de Gastroentérologie et d'Oncologie Digestive, Hôpital Edouard Herriot, Hospices Civils de Lyon, \\ F69437 Lyon, France \\ 5 Service de Radiologie, Hôpital Edouard Herriot, Hospices Civils de Lyon, F69437 Lyon, France \\ 6 Service Central d'Anatomie et Cytologie Pathologiques, Hôpital Edouard Herriot, Hospices Civils de Lyon, \\ F69437 Lyon, France \\ * Correspondence: arnaud.pasquer@chu-lyon.fr; Tel.: +33-472-116-922; Fax: +33-472-116-783
}

Citation: Pasquer, A.; Walter, T.; Milot, L.; Hervieu, V.; Poncet, G. Principles of Surgical Management of Small Intestinal NET. Cancers 2021, 13, 5473. https://doi.org/10.3390/ cancers13215473

Academic Editor: Guido Rindi

Received: 27 September 2021

Accepted: 28 October 2021

Published: 30 October 2021

Publisher's Note: MDPI stays neutral with regard to jurisdictional claims in published maps and institutional affiliations.

Copyright: (C) 2021 by the authors Licensee MDPI, Basel, Switzerland. This article is an open access article distributed under the terms and conditions of the Creative Commons Attribution (CC BY) license (https:// creativecommons.org/licenses/by/ $4.0 /)$.
Simple Summary: Small-intestinal neuroendocrine tumors (siNETs) account for $25 \%$ of gastroenteropancreatic NETs. A total of $89 \%$ of multiple tumors are located in the ileum, often within $100 \mathrm{~cm}$ of the ileocecal valve. According to current guidelines, all localized siNETs should be considered for radical resection with lymphadenectomy. The preoperative workout should focus on symptoms of carcinoid syndrome (flush, diarrhea, and cardiac failure). Morphological evaluation should include a CT scan with a thin-slice arterial CT, a PET/CT with $68 \mathrm{Ga}$, and a hepatic MRI. Levels of $24 \mathrm{~h}$ urinary 5-hydroxyindoleacetic acid are needed. Regarding surgery, the limiting component is the number of free jejunal branches allowing a resection without risk of short small bowel syndrome. In case of emergency surgery, there is expert agreement that it is not reasonable to initiate resection of the mesenteric mass without comprehensive workup and mapping. The challenge lies in the ability to propose a resection without imposing short small bowel syndrome on the patients.

Abstract: Introduction: Small-intestinal neuroendocrine tumors (siNETs) account for 25\% of gastroenteropancreatic NETs. Multiple siNETs appear to develop in a limited segment of the small bowel (SB), $89 \%$ of them being located in the ileum, most often within $100 \mathrm{~cm}$ of the ileocecal valve (ICV). According to the European Neuroendocrine Tumor Society (ENETS) and the American Joint Committee on Cancer (AJCC), all localized siNETs should be considered for radical surgical resection with adequate lymphadenectomy irrespective of the absence of lymphadenopathy or mesenteric involvement. Surgical management of siNETs: The preoperative workout should include a precise evaluation of past medical and surgical history, focusing on the symptoms of carcinoid syndrome (flush, diarrhea, and cardiac failure). Morphological evaluation should include a CT scan including a thin-slice arterial CT, a PET/CT with $68 \mathrm{Ga}$, and a hepatic MRI in cases of suspected metastasis. Levels of $24 \mathrm{~h}$ urinary 5-hydroxyindoleacetic acid are needed. Regarding surgery, the limiting component is the number of free jejunal branches allowing a resection without risk of short small bowel syndrome. The laparoscopic approach has been poorly studied, and open laparotomy remains the gold standard to explore the abdominal cavity and entirely palpate the small bowel through bidigital palpation and compression. An extensive lymphadenectomy is required. A prophylactic cholecystectomy should be performed. In case of emergency surgery, current recommendations are not definitive. However, there is expert agreement that it is not reasonable to initiate resection of the mesenteric mass without comprehensive workup and mapping. Conclusion: The surgery of siNETs is in constant evolution. The challenge lies in the ability to propose a resection without imposing short small bowel syndrome on the patients. The oncological benefits supported in the literature led to recent changes in the recommendations of academic societies. The next steps remain the dissemination of reproducible quality criteria to perform these procedures. 
Keywords: small bowel neuroendocrine tumors; surgery; lymphadenectomy

\section{Introduction}

Small-intestinal neuroendocrine tumors (siNETs) account for $25 \%$ of gastroenteropancreatic NETs [1], but their incidence has increased by $300-500 \%$ over the past 40 years [2]. siNETs have the particularity of being multiple in $30-56 \%$ of cases and are often diagnosed at metastatic stage in 50\% of cases [3-6]. There is currently no known pathogenetic mechanism underlying the development of multiple tumors, and prognosis is similar to that of unifocal siNETs [5,6]. Multiple siNETs appear to develop in a limited segment of the small bowel (SB), $89 \%$ of them being located in the ileum, most often within $100 \mathrm{~cm}$ of the ileocecal valve (ICV) [7]. Current Europe and Neuroendocrine Tumor Society (ENETS) recommendations propose resecting the primitive tumor(s) even when metastatic in order to prevent local morbidity (ischemia, digestive perforation, and occlusion) [8]. In small/incidentally found lesions, resection with local lymphadenectomy should be performed when pathology is unknown. In locoregionally advanced disease, radical resection with extent lymphadenectomy should be proposed due to the local evolutive risk. Resection is still debated in metastatic conditions; nevertheless, local resection at the origin of mesenteric arteries can prevent locoregional complications. Such benefits should imply discussion around surgery in metastatic context. Nodes dissections are not standardized and rely on lymph node extension. The resection of at least seven lymph nodes is correlated with an improvement in overall survival [9]. Recently, an embryological theory emerged to locate unique and multiple tumors, on the basis of the fact that multiple siNETs are mostly located on the left side of the superior mesenteric artery axis [10] (Figure 1). According to ENETS and the American Joint Committee on Cancer (AJCC), all localized siNETs require radical surgical resection with adequate lymphadenectomy irrespective of the absence of lymphadenopathy or mesenteric involvement. We here describe a standardized surgical procedure to oncologically resect those siNETs.

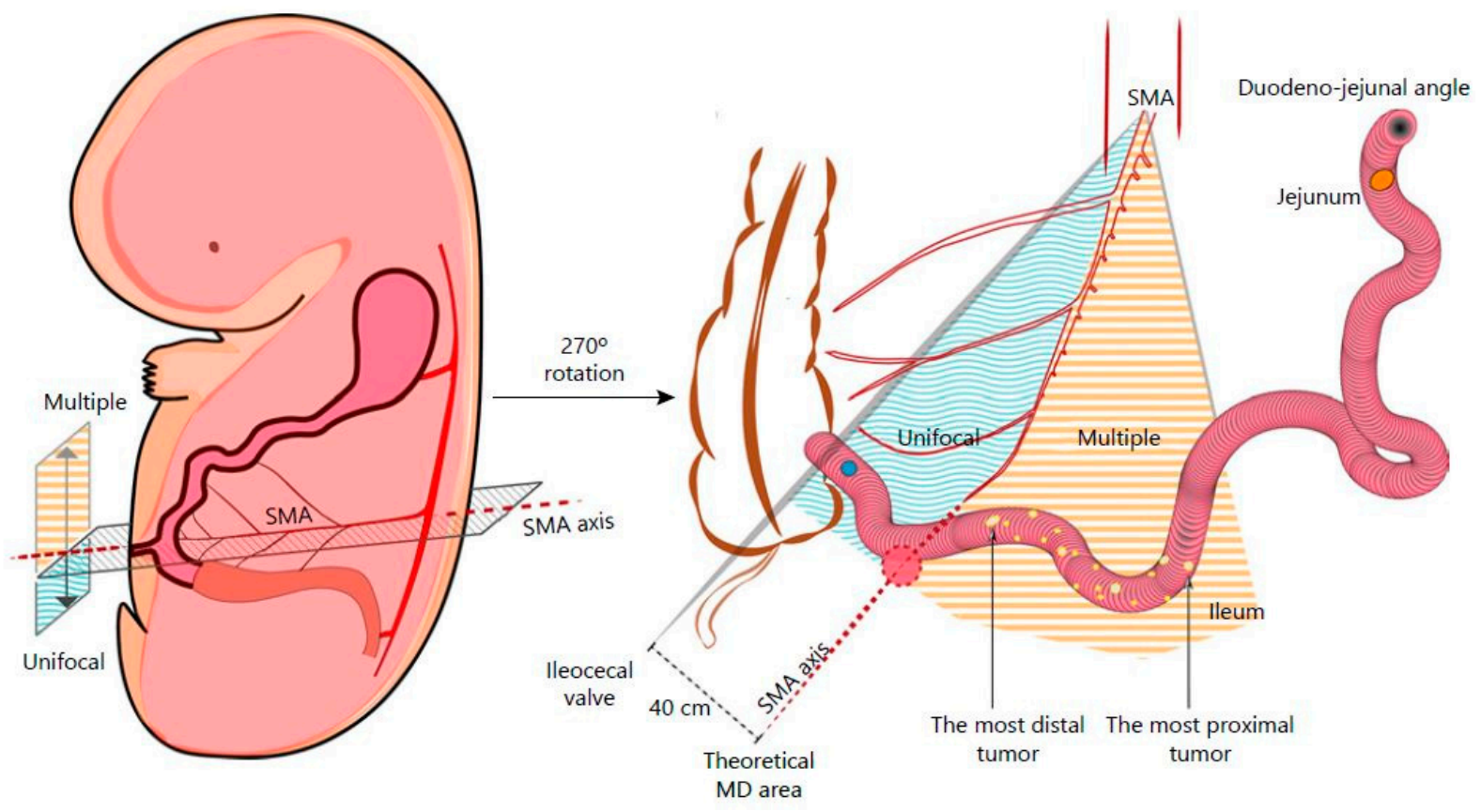

Figure 1. Embryological theory of single or multiple tumors. Figure issued from Kalifi, M., Walter, T., Milot, L., et al.: Unifocal versus Multiple Ileal Neuroendocrine Tumors Location: An Embryological Origin. Neuroendocrinology 2021; 111: 786-793. DOI: 10.1159/000511849. Reproduced with permission of S. Karger AG [10]. 


\section{Scheduled Surgery}

\subsection{Preoperative Workout}

According to the ENETS consensus guidelines [8], the preoperative workout should include a precise evaluation of past medical and surgical history, focusing on the symptoms of carcinoid syndrome (flush, diarrhea, and cardiac failure). Cardiological evaluation should be mandatory to detect tricuspid or pulmonary failure. Morphological evaluation should include a triphasic CT scan including a thin-slice arterial CT angiography (CTA) of the abdomen and pelvis allowing three-dimensional reconstruction to evaluate the vascular involvement [11,12], a PET/CT with $68 \mathrm{Ga}$ (sensitivity of 90\%), and a hepatic MRI in cases of suspected metastasis [8]. siNETs are sometimes difficult to see on CT scans, but mesenteric lesions appear as contrast-enhancing and surrounded by striae of desmoplastic reaction. Levels of $24 \mathrm{~h}$ urinary 5 -hydroxyindoleacetic acid are given but not specific and used only for their prognostic utility. The interest in the three-dimensional reconstruction is multiple: it allows prediction of the extension of the lymph node involvement and anticipation of the resectability according to the Deguelte's classification [13]. Mesenteric mass invasion is divided into four stages according to its location regarding the superior mesenteric artery (SMA): stage I: proximity to the small intestine; stage II: involvement of the distal branches of the SMA; stage III up: involvement of the trunk of the SMA with $<3-4$ free jejunal branches; stage III down: $>3-4$ free jejunal branches; stage IV: involvement of the first jejunal arteries. The limiting component is the number of free jejunal branches allowing a resection without risk of short small bowel syndrome. It is important to standardize the reconstruction technique including arterial and venous vascularization with the mesenteric mass (Figure 2). Patients who are unfit for surgery are the ones presenting peripancreatic vessel involvement (superior mesenteric vein, superior mesenteric artery, coeliac axis, and proper hepatic artery).
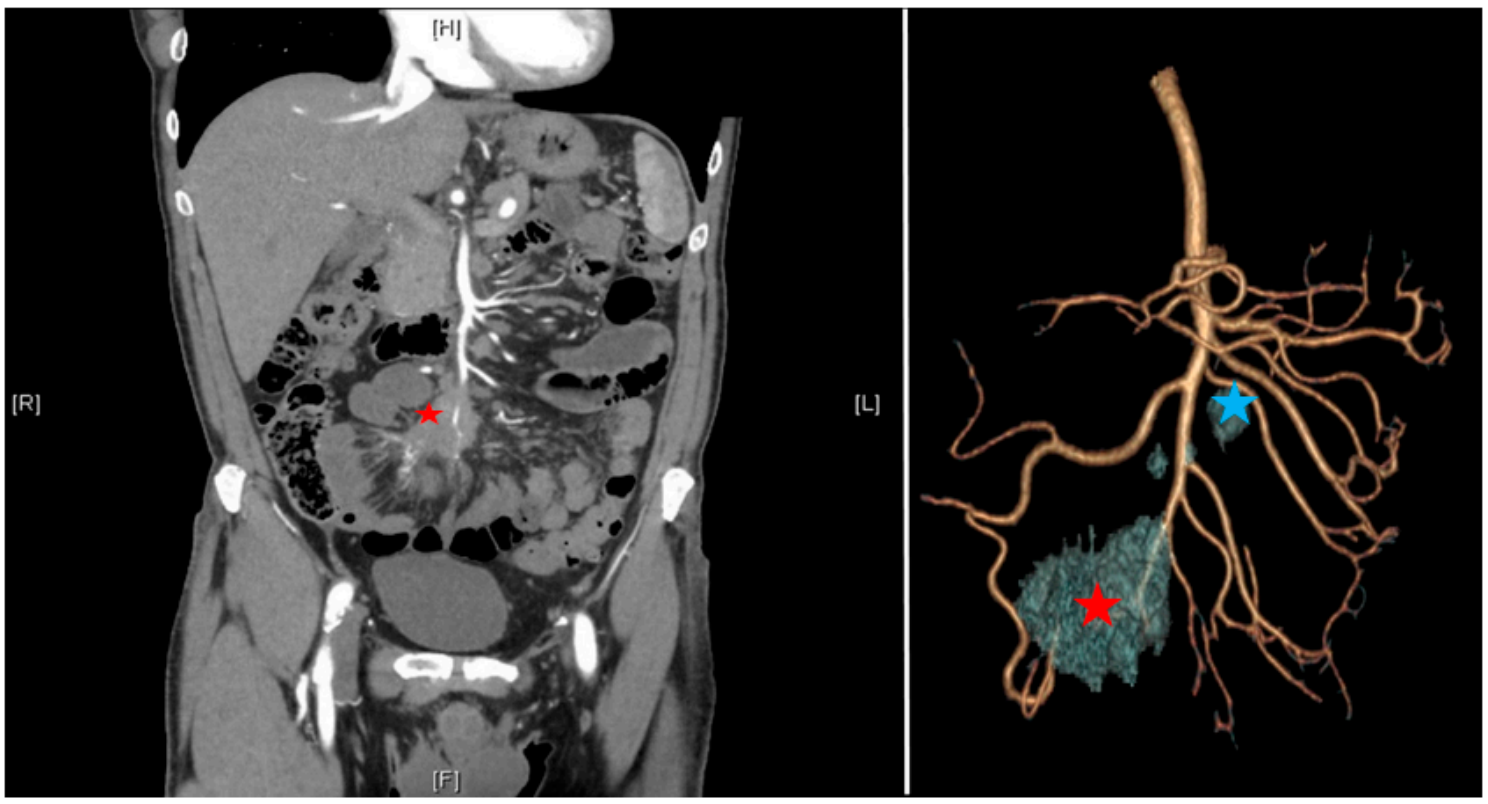

Figure 2. CT scan with arterial three-dimensional reconstruction; mesenteric mass (red star); proximal nodes (group 3 down from Deguelte et al. [13] in blue star).

Patients with carcinoid syndrome received a continuous infusion of octreotide (2000 $\mu \mathrm{g} /$ day) at least $12 \mathrm{~h}$ before surgery, during, and at least $24 \mathrm{~h}$ after surgery in order to prevent perioperative carcinoid syndrome [6]. Octreotide administration aims to saturate type 2 serotonin receptors to reduce intraoperative hemodynamic risk when handling liver metastases, carcinosis lesions, or mesenteric masses. These intraoperative flushes can be fatal in the absence of saturation of these receptors. 


\subsection{Centralization of Procedures}

For several years, the impact of centralization in digestive surgery on postoperative outcomes and the centralization of activity in expert centers has been debated regarding all areas of this surgical specialty, as well as in other specialties. The vast majority of these studies showed a reduction in postoperative complications and length of stay, regardless of the severity of the pathology, the type of surgery, or the patients' comorbidities [14-17]. Reflections around centralization for siNET surgery are rising. We performed a pilot evaluation in our regional RENATEN center. It appears that lymph node resection was $>12$ nodes when performed in expert centers in $93 \%$ of cases versus $68 \%$. The same observations were found regarding the rate of multiple tumors found: $46 \%$ vs. $26 \%$. A French national study is underway to address this issue.

\subsection{Laparotomy or Laparoscopy}

The laparoscopic approach has been poorly studied. In most published studies, laparotomy is the reference approach. It allows for a much more precise evaluation of the peritoneal and mesenteric involvement if necessary; it allows for a better control of the origin of the mesenteric vessels in case of extensive nodal resection [6,18]. Similarly, systematic palpation of the small intestine is hardly feasible in laparoscopy and increases the risk of missing a small bowel lesion (up to $80 \%$ of cases after suboptimal surgery). This risk is currently being investigated by Deguelte et al. On the other hand, Kaçmaz et al. recently reported the feasibility of the laparoscopic approach in a cohort of 34 operated patients (11 open and 23 minimally invasive). A conversion to laparotomy with a $10 \mathrm{~cm}$ incision was necessary in $30 \%$ of the patients in the laparoscopic group because of difficulties in exposing the mesenteric root. The laparoscopic approach was safe regarding postoperative complications as well as oncological data (although in the overall cohort, five patients were classified R1 (14.7\%) and two patients R2 (5.8\%)). The distance between the nodal mass and the mesenteric axis did not differ between the groups. To explore the entire bowel, a $10 \mathrm{~cm}$ laparotomy was routinely performed to carefully palpate the small bowel. The authors concluded that the laparoscopic approach was feasible in a tertiary referral center [19]. Finally, regarding the ovarian and peritoneal metastatic implication ( $14 \%$ in our cohort), laparotomy appears to be the best approach in a curative intent to perform a complete cytoreductive surgery.

\subsection{Exploration of the Abdomen}

As a first step, the abdominal cavity is explored, and the full length of the small bowel is analyzed visually and through bidigital palpation and compression. Any suspected tumors are tagged with a polypropylene suture. The distance from the most proximally suspected tumor to the ileocecal valve is noted in order to predict the future length of the residual small bowel.

Then, visual searches for miliary liver metastases are systematically performed, as well as perioperative ultrasounds and liver biopsies. Liver ultrasonography is always necessary to define the diagnosis of liver involvement. Peritoneal metastases are searched, and finally, the ovaries are examined to detect invasion.

\subsection{Cholecystectomy}

Somatostatin analogs represent a main part of the postoperative (in case of R1 and $\mathrm{R} 2$ resection) oncological treatment. Those molecules are known to expose patients to the risk of gallbladder stone formation. Prophylactic cholecystectomy can be safely performed without major increase in postoperative morbidity in cholecystectomy vs. no cholecystectomy groups $(11.8 \%$ vs. $11.1 \%$, respectively; $p=0.79)$ or mortality $(1.4 \%$ vs. $0.6 \%$, respectively; $p=0.29$ ) [20]. To prevent any gallbladder complication (or necrosis in case of future arterial embolization), a prophylactic cholecystectomy should be performed [1]. Therefore, further prospective studies should be performed to identify which patients may benefit from this approach, as stated by Sinnamon et al. [20]. 


\subsection{Extensive Lymphadenectomy}

To date, five teams have reported positive oncological results arguing for extensive lymph node dissection (Table 1).

Table 1. Summary of extensive lymphadenectomy literature.

\begin{tabular}{|c|c|c|c|c|c|c|}
\hline Ref. & Year & $\begin{array}{l}\text { First } \\
\text { Author }\end{array}$ & $\begin{array}{c}\text { Number of } \\
\text { Patients }\end{array}$ & $\begin{array}{l}\text { Threshold of } \\
\text { Harvested } \\
\text { Nodes }\end{array}$ & $\begin{array}{l}\text { Threshold } \\
\text { of Invaded } \\
\text { Nodes }\end{array}$ & Main Result \\
\hline [9] & 2013 & Landry & 1364 & 7 & - & $\begin{array}{l}\text { The number of harvested } \\
\text { nodes has positive impact } \\
\text { on specific survival }\end{array}$ \\
\hline [6] & 2015 & Pasquer & 107 & - & - & $\begin{array}{c}\text { node recurrence rate } 12 \%, \\
5 \text { year recurrence-free } \\
\text { survival } 88 \%\end{array}$ \\
\hline [21] & 2018 & Motz & 11852 & 8 & - & $\begin{array}{l}8 \text { nodes are needed to } \\
\text { identify patients with } \\
\text { nodal metastasis, the rate } \\
\text { of harvested node is } \\
\text { predictive of survival }\end{array}$ \\
\hline [22] & 2018 & Cives & 129 & 17 & - & $\begin{array}{l}\text { Harvested nodes was } \\
\text { associated to the } \\
\text { recurrence risk and shorter } \\
\text { disease-free survival }\end{array}$ \\
\hline [23] & 2019 & Zaidi & 199 & - & 4 & $\begin{array}{l}>4 \text { invaded nodes is } \\
\text { significantly associated } \\
\text { with poorer } 3 \text { year } \\
\text { recurrence-free survival }\end{array}$ \\
\hline
\end{tabular}

Landry et al. described a threshold of seven harvested nodes to have a positive impact on specific survival. The main limitation of this study was that $30 \%$ had no lymph nodes analyzed on the surgical specimen [9]. Pasquer et al. reported a low lymph node recurrence rate of $12 \%$ with a 5 year recurrence-free survival of $88 \%$ in case of extensive curage with a mean follow-up of 54 months. The benefit on overall survival was not achieved due to a lack of statistical power [6]. More recently, Motz et al. described a 79.3\% rate of node positivity in 11,852 patients, despite the fact that $46.9 \%$ of patients had primary lesions of less than $1 \mathrm{~cm}$. A threshold of eight nodes was used to reliably identify patients with or without lymph node metastasis. Finally, an extensive lymph node resection with a reduced ratio of invaded to benign nodes was predictive of survival [21]. A later study by Zaidi et al. reported that the presence of at least four invaded nodes was significantly associated with poorer 3 year recurrence-free survival ( $82 \%$ vs. $92 \%$ if $<4 \mathrm{~N}+; p=0.01$ ). In addition, patients with more extensive lymph node resection ( $\geq 8$ nodes) had different survivals based on the number of nodes involved (3 year recurrence-free survival: $93 \%$, $90 \%$, and $80 \%$ if $0,1-3, \geq 4 \mathrm{~N}+$, respectively; $p=0.047$ ) [23]. Finally, Cives et al. reported on 129 patients with siNETs operated on with oncological data. Regarding lymph node resection, a threshold of more than 17 harvested nodes was associated with the recurrence risk and shorter disease-free survival [22].

The definition of an extensive lymph node dissection is still debated. However, complications related to the mesenteric mass appear when the compression is proximal, either by further progression or by lymph node recurrence. Three lymph node groups have been described: group 1 in contact with the small bowel, group 2 in the middle of the mesentery, and group 3 at the origin of the mesenteric vessels under the pancreatic uncus. In the cohort of Pasquer et al. [24], the phenomenon of skip metastases was objectified (Figure 3). This nodal bypass corresponds to an involvement of the proximal lymph nodes (i.e., groups 2 and 3 ) while the lymph nodes in contact with the intestine (group 1) are not invaded. This phenomenon appeared in $66 \%$ of patients. These data published in 2016 were updated locally in 2019, finding those skip metastases in $69 \%$ of cases, but not published. 


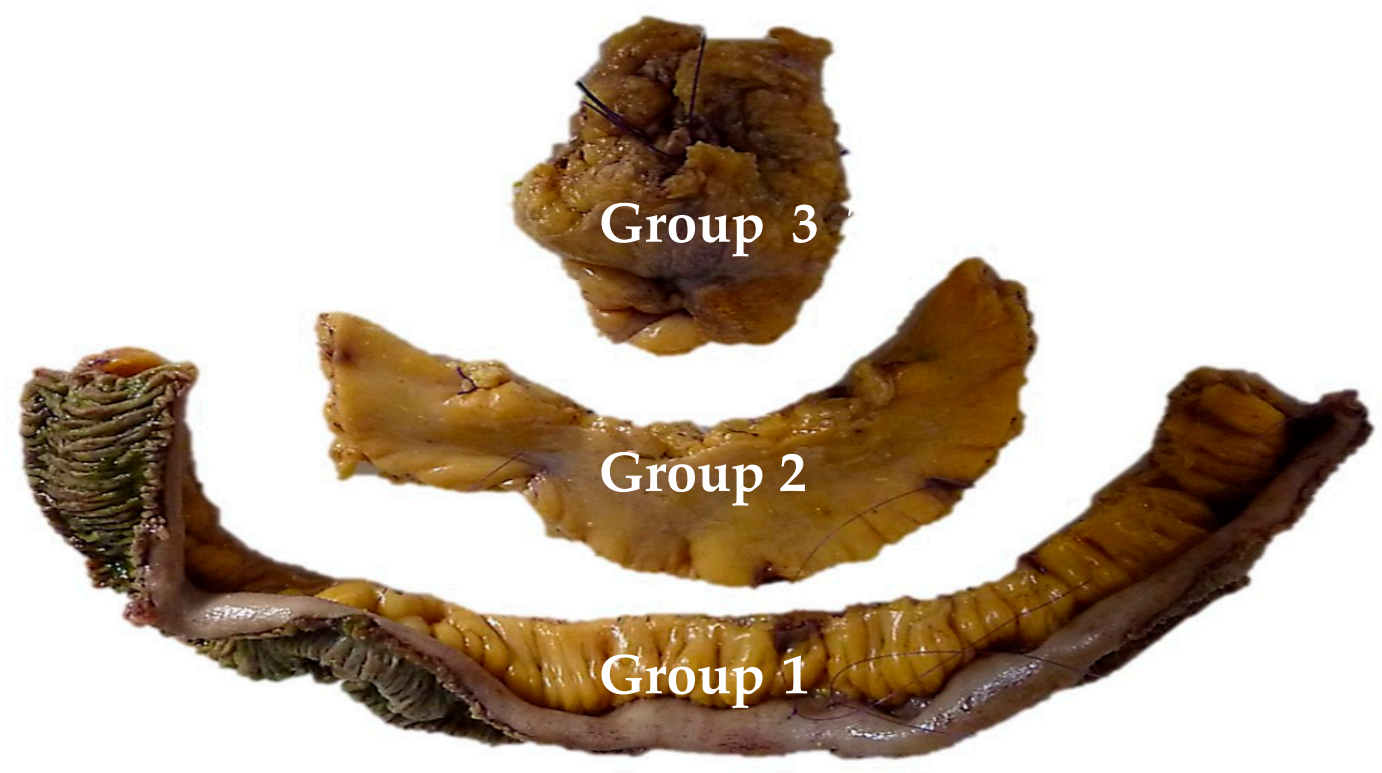

Figure 3. Showing the three nodal groups whose resection is recommended. Figure issued from Pasquer, A., Walter, T., Rousset, P., et al. Lymphadenectomy during Small Bowel Neuroendocrine Tumor Surgery: The Concept of Skip Metastases. Ann Surg Oncol. 2016; 23 (Suppl 5): 804-808. Doi: 10.1245/s10434-016-5574-8. Reproduced with permission of Springer nature [23].

\subsection{Resection of the Primitive Lesions and Mesenteric Tumor-Technical Points}

The resection starts with dissection of the mesenteric vessels to determine whether the mesenteric nodal block is resectable. Then, the retroperitoneum is opened, followed by a Kocher maneuver to expose the proximal part of the superior mesenteric artery. This strategy allows progressive ligation of vascular branches without any threat to uninvaded jejunal arteries. Lymphadenectomy is performed above the right colic vessels if the nodal mass is located on the right part of the mesenteric axis. If the nodal mass only implies the left side of mesenteric artery, the right superior colic artery can be preserved if the mass is located below its origin. Right hemicolectomy is not mandatory in all patients. Next, the dissection is pursued on the left border of the superior mesenteric vessels. A minimum of three jejunal branches have to be free to avoid the risk of short bowel length $[6,13]$. Then, the length of the devascularized small bowel determines the resection's limit (Figure 4). Due to the collateral circulation, the ischemic small bowel segment is usually shorter than expected. Extensive lymphadenectomy can be performed from the small bowel section to the superior mesenteric dissection, with special attention paid to any jejunal pedicle that could be preserved (Figure 5). The length of the remaining small bowel should be measured and recorded. Techniques of reconstruction do not differ from any digestive surgery anastomosis and should be performed according to the experience of the operator.

\subsection{Operating Report}

To date, there are no recommendations concerning the content of the operative report. Nevertheless, we have standardized it and propose the following content.

Concerning the clinical history, it must be complete, associating all the preoperative morphological and biological workup, including the stability of the carcinoid syndrome and the preoperative preparation with octreotide. 


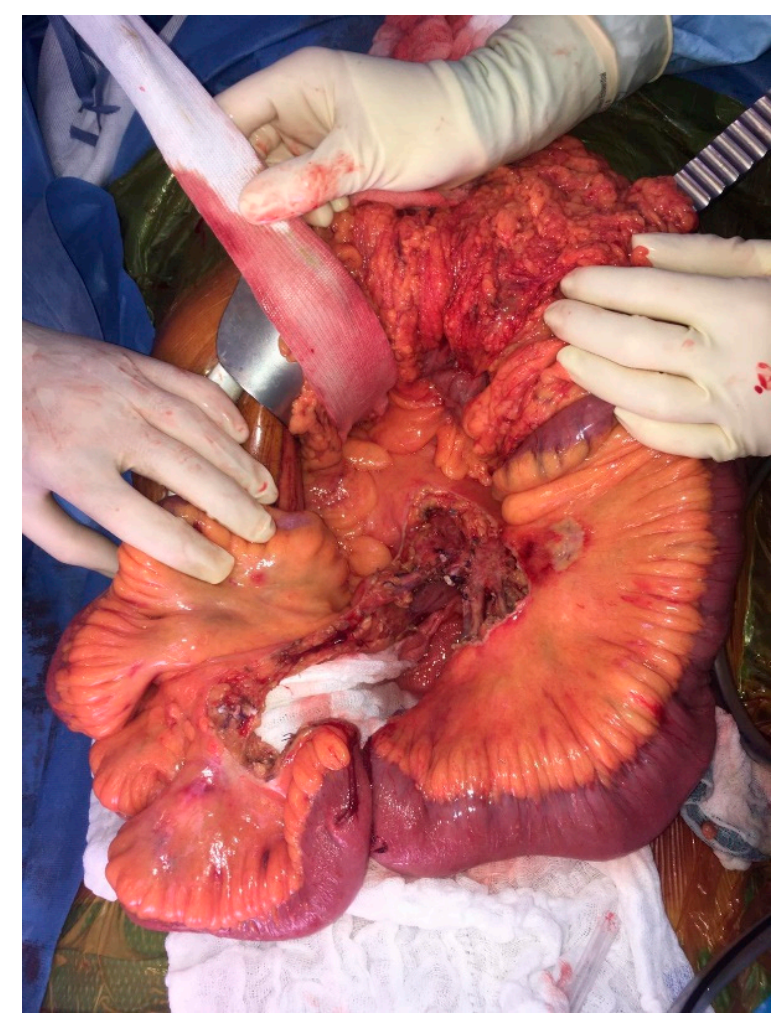

Figure 4. Operative view showing the persisting small bowel after resection (on the proximal side, $2.50 \mathrm{~m}$ was preserved; on the distal segment, $1 \mathrm{~m}$ was persistent).

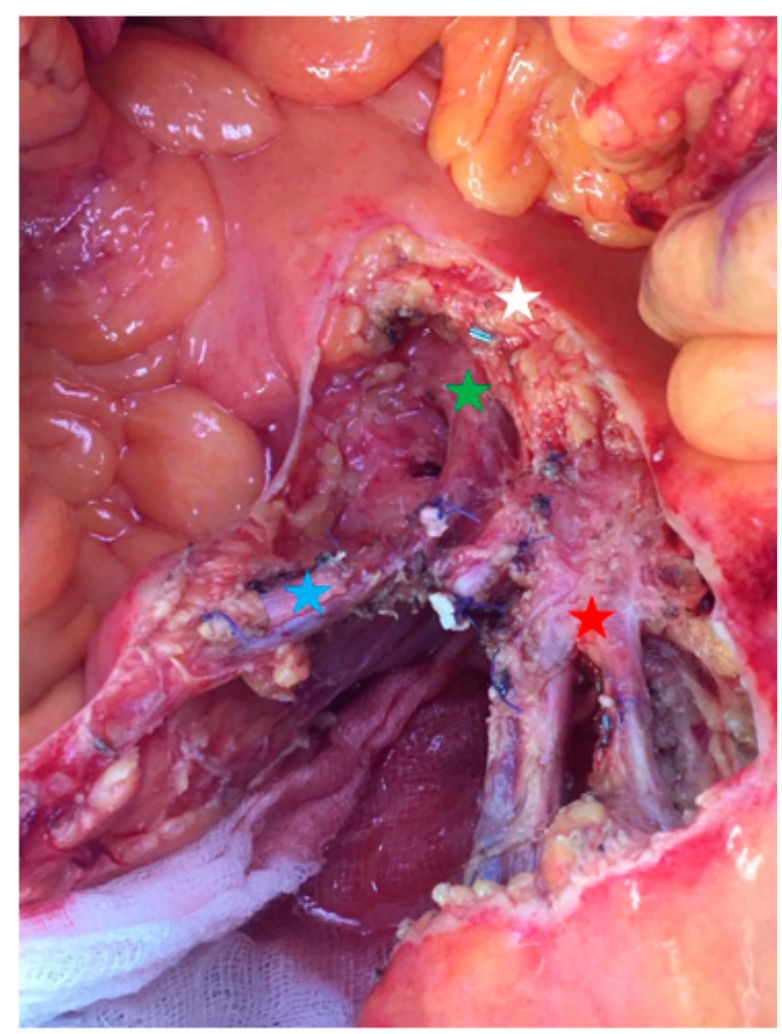

Figure 5. Operative view focusing on the proximal nodal resection (group 3). Red star: proximal jejunal arteries and veins; blue star: superior right colic artery and vein; green star: superior mesenteric vein; white star: pancreas. 
Concerning the procedure, the exploration phase must be meticulously described, including:

- At the hepatic level: the presence of a miliary, the location of lesions, the realization of biopsy, and ultrasonography report.

- $\quad$ Mapping of the carcinosis.

- Description of ovarian involvement.

- The number of tumors, their location in relation to the mesenteric axis.

- Classification of the mesenteric mass as resectable type 1 to 4 .

- Measurements between the Treitz angle and the first lesion, the resected length and the length downstream to the ileocecal valve.

- The need for a right colectomy.

Concerning anesthetic management, it is important to specify the hemodynamic stability and the presence of flushing during the operation (concomitant with hepatic, ovarian, or other mobilization).

\subsection{Oophorectomy}

A systematic bilateral oophorectomy in case of clinical complaint (such as heaviness or pelvic pain) or carcinoid syndrome and in the presence of ovarian metastases [25] should be performed. We also suggest a systematic oophorectomy if a carcinoid crisis occurs when touching or moving the ovaries during dissection. In young patients, oophorectomy should be realized after extemporaneous pathological study proving NET lesions. Finally, oophorectomy should be discussed in postmenopausal women.

\section{Emergency Surgery}

Occlusive syndrome on retractile mesenteritis or mesenteric ischemia constitutes the main emergencies secondary to a complication of siNETs by local invasion. These patients are sometimes diagnosed at the stage of the complication. Current recommendations are not definitive. However, there is expert agreement that it is not reasonable to initiate resection of the mesenteric mass without comprehensive workup and mapping. It would then seem appropriate to treat the complication if there are signs of severity. It is quite possible to medically treat venous ischemia without necrosis before transferring the patient to an expert center. However, in case of occlusion with signs of severity (ischemia, ascites, septic shock, etc.) or acute arterial ischemia, an intervention to overcome this episode should be proposed. Due to the difficulties of exposition induced by the dilation of the bowel, the risk of missing a tumoral lesion is high, as well as the risk of hemorrhage. Mesenteritis makes dissection difficult, and dilatation of the bowel makes the vascular division even more difficult. Surgery in context of emergency will consist of a resection of the ischemic segments or a simple offloading stoma upstream of the mesenteric mass before transferring the patient to an expert center [8]. It appears dangerous in a complicated situation to approach the origin of the mesenteric vessels with a risk of cataclysmic hemorrhage.

\section{Conclusions}

The surgery of siNETs is in constant evolution. Recent studies plead for resection of primary lesions even in metastatic condition in order to preserve patients from the risk of occlusion or mesenteric ischemia. The challenge lies in the ability to propose a resection without imposing short small bowel syndrome on the patients, which is synonymous with quasi-definitive parenteral nutrition as a complement. The oncological benefits supported in the literature led to recent changes in the recommendations of academic societies. The next steps are the dissemination of reproducible quality criteria as described in this manuscript, as well as the definition of expert centers able to perform these procedures (in parallel with the ENETS expert centers from an oncological point of view). 
Author Contributions: Conceptualization, A.P. and G.P.; methodology, A.P.; validation, T.W., L.M., V.H. and G.P.; resources, A.P.; writing—original draft preparation, A.P. and G.P.; writing—review and editing, A.P., T.W., L.M., V.H. and G.P. All authors have read and agreed to the published version of the manuscript.

Funding: This research received no external funding.

Institutional Review Board Statement: Not applicable for studies not involving humans or animals. Informed Consent Statement: Not applicable.

Data Availability Statement: No new data were created or analyzed in this study. Data sharing is not applicable to this article.

Conflicts of Interest: The authors declare no conflict of interest.

\section{References}

1. Pasquer, A.; Poncet, G. Small bowel neuroendocrine tumors surgery: Technical point-With video. J. Visc. Surg. 2017, 154, 61-62. [CrossRef] [PubMed]

2. Dasari, A.; Shen, C.; Halperin, D.M.; Zhao, B.; Zhou, S.; Xu, Y.; Shih, T.; Yao, J.C. Trends in the Incidence, Prevalence, and Survival Outcomes in Patients With Neuroendocrine Tumors in the United States. JAMA Oncol. 2017, 3, 1335-1342. [CrossRef] [PubMed]

3. Gangi, A.; Siegel, E.; Barmparas, G.; Lo, S.; Jamil, L.H.; Hendifar, A.; Nissen, N.N.; Wolin, E.M.; Amersi, F. Multifocality in Small Bowel Neuroendocrine Tumors. J. Gastrointest. Surg. 2017, 22, 303-309. [CrossRef]

4. Strosberg, J.R.; Weber, J.M.; Feldman, M.; Coppola, D.; Meredith, K.; Kvols, L.K. Prognostic Validity of the American Joint Committee on Cancer Staging Classification for Midgut Neuroendocrine Tumors. J. Clin. Oncol. 2013, 31, 420-425. [CrossRef] [PubMed]

5. Yantiss, R.K.; Odze, R.; Farraye, F.A.; Rosernberg, A.E. Solitary Versus Multiple Carcinoid Tumors of the Ileum. Am. J. Surg. Pathol. 2003, 27, 811-817. [CrossRef]

6. Pasquer, A.; Walter, T.; Hervieu, V.; Forestier, J.; Scoazec, J.-Y.; Lombard-Bohas, C.; Poncet, G. Surgical Management of Small Bowel Neuroendocrine Tumors: Specific Requirements and Their Impact on Staging and Prognosis. Ann. Surg. Oncol. 2015, 22, 742-749. [CrossRef]

7. Keck, K.J.; Maxwell, J.E.; Utria, A.F.; Bellizzi, A.; Dillon, J.; O’Dorisio, T.; Howe, J.R. The Distal Predilection of Small Bowel Neuroendocrine Tumors. Ann. Surg. Oncol. 2018, 25, 3207-3213. [CrossRef] [PubMed]

8. Partelli, S.; Bartsch, D.K.; Capdevila, J.; Chen, J.; Knigge, U.; Niederle, B.; Van Dijkum, E.J.M.N.; Pape, U.-F.; Pascher, A.; Ramage, J.; et al. ENETS Consensus Guidelines for the Standards of Care in Neuroendocrine Tumours: Surgery for Small Intestinal and Pancreatic Neuroendocrine Tumours. Neuroendocrionlogy 2017, 105, 255-265. [CrossRef]

9. Landry, C.S.; Lin, H.Y.; Phan, A.; Charnsangavej, C.; Abdalla, E.K.; Aloia, T.; Vauthey, J.N.; Katz, M.H.G.; Yao, J.C.; Fleming, J.B. Resection of At-Risk Mesenteric Lymph Nodes Is Associated with Improved Survival in Patients with Small Bowel Neuroendocrine Tumors. World J. Surg. 2013, 37, 1695-1700. [CrossRef]

10. Kalifi, M.; Walter, T.; Milot, L.; Hervieu, V.; Millot, I.; Gibert, B.; Roche, C.; Forestier, J.; Lombard-Bohas, C.; Pasquer, A.; et al. Unifocal versus Multiple Ileal Neuroendocrine Tumors Location: An Embryological Origin. Neuroendocrinology 2021, 111, 786-793. [CrossRef]

11. Clift, A.K.; Faiz, O.; Nahhas, A.; Bockisch, A.; Liedke, M.O.; Schloericke, E.; Wasan, H.; Martin, J.; Ziprin, P.; Moorthy, K.; et al. Role of Staging in Patients with Small Intestinal Neuroendocrine Tumours. J. Gastrointest. Surg. 2015, 20, 180-188. [CrossRef]

12. Dahdaleh, F.S.; Lorenzen, A.; Rajput, M.; Carr, J.C.; Liao, J.; Menda, Y.; O’Dorisio, T.M.; Howe, J.R. The Value of Preoperative Imaging in Small Bowel Neuroendocrine Tumors. Ann. Surg. Oncol. 2013, 20, 1912-1917. [CrossRef] [PubMed]

13. Deguelte, S.; Perrier, M.; Hammoutene, C.; Cadiot, G.; Kianmanesh, R. Surgery and Perioperative Management in Small Intestinal Neuroendocrine Tumors. J. Clin. Med. 2020, 9, 2319. [CrossRef]

14. Pasquer, A.; Renaud, F.; Hec, F.; Gandon, A.; Vanderbeken, M.; Drubay, V.; Caranhac, G.; Piessen, G.; Mariette, C. Is Centralization Needed for Esophageal and Gastric Cancer Patients With Low Operative Risk? A Nationwide Study. Ann. Surg. 2016, 264, 823-830. [CrossRef] [PubMed]

15. El Amrani, M.; Lenne, X.; Clement, G.; Delpero, J.R.; Theis, D.; Pruvot, F.-R.; Bruandet, A.; Truant, S. Specificity of Procedure volume and its Association With Postoperative Mortality in Digestive Cancer Surgery: A Nationwide Study of 225,752 Patients. Ann. Surg. 2019, 270, 775-782. [CrossRef]

16. Kaplan, G.G.; McCarthy, E.P.; Ayanian, J.Z.; Korzenik, J.; Hodin, R.; Sands, B.E. Impact of Hospital Volume on Postoperative Morbidity and Mortality Following a Colectomy for Ulcerative Colitis. Gastroenterology 2008, 134, 680-687.e1. [CrossRef] [PubMed]

17. Aquina, C.T.; Probst, C.P.; Becerra, A.Z.; Iannuzzi, J.; Kelly, K.N.; Hensley, B.J.; Rickles, A.S.; Noyes, K.; Fleming, F.; Monson, J.R. High volume improves outcomes: The argument for centralization of rectal cancer surgery. Surgery 2016, 159, 736-748. [CrossRef] 
18. Figueiredo, M.; Maggiori, L.; Gaujoux, S.; Couvelard, A.; Guedj, N.; Ruszniewski, P.; Panis, Y. Surgery for small-bowel neuroendocrine tumors: Is there any benefit of the laparoscopic approach? Surg. Endosc. 2014, 28, 1720-1726. [CrossRef] [PubMed]

19. Kaçmaz, E.; van Eeden, S.; Koppes, J.C.; Klümpen, H.-J.; Bemelman, W.A.; van Dijkum, E.J.N.; Engelsman, A.F.; Tanis, P.J. Value of Laparoscopy for Resection of Small Bowel Neuroendocrine Neoplasms Including Central Mesenteric Lymphadenectomy. Dis. Colon Rectum 2021, 64, 1240-1248. [CrossRef]

20. Sinnamon, A.J.; Neuwirth, M.G.; Vining, C.C.; Sharoky, C.E.; Yang, Y.-X.; Kelz, R.R.; Fraker, U.L.; Roses, R.E.; Karakousis, G.C. Prophylactic Cholecystectomy at Time of Surgery for Small Bowel Neuroendocrine Tumor Does Not Increase Postoperative Morbidity. Ann. Surg. Oncol. 2018, 25, 239-245. [CrossRef] [PubMed]

21. Motz, B.M.; Lorimer, P.D.; Boselli, D.; Hill, J.S.; Salo, J.C. Optimal Lymphadenectomy in Small Bowel Neuroendocrine Tumors: Analysis of the NCDB. J. Gastrointest. Surg. 2017, 22, 117-123. [CrossRef] [PubMed]

22. Cives, M.; Anaya, D.A.; Soares, H.; Coppola, D.; Strosberg, J. Analysis of postoperative recurrence in stage I-III Midgut Neuroen-docrine Tumors. JNCI J. Natl. Cancer Inst. 2018, 110, 282-289. [CrossRef]

23. Zaidi, M.Y.; Lopez-Aguiar, A.G.; Dillhoff, M.; Beal, E.; Poultsides, G.; Makris, E.; Rocha, F.; Crown, A.; Idrees, K.; Smith, P.M.; et al. Prognostic Role of Lymph Node Positivity and Number of Lymph Nodes Needed for Accurately Staging Small-Bowel Neuroendocrine Tumors. JAMA Surg. 2019, 154, 134-140. [CrossRef] [PubMed]

24. Pasquer, A.; Walter, T.; Rousset, P.; Hervieu, V.; Forestier, J.; Lombard-Bohas, C.; Poncet, G. Lymphadenectomy during Small Bowel Neuroendocrine Tumor Surgery: The Concept of Skip Metastases. Ann. Surg. Oncol. 2016, 23, 804-808. [CrossRef] [PubMed]

25. Pavel, M.; Grossman, A.; Arnold, R.; Perren, A.; Kaltsas, G.; Steinmüller, T.; De Herder, W.; Nikou, G.; Plöckinger, U.; Lopes, J.M.; et al. ENETS Consensus Guidelines for the Management of Brain, Cardiac and Ovarian Metastases from Neuroendocrine Tumors. Neuroendocrinology 2010, 91, 326-332. [CrossRef] 